\title{
EFFECTS OF DESALINATION ON HYDRODYNAMIC PROCESS IN PERSIAN GULF
}

\author{
Wonhyun Lee ${ }^{1}$ and James M. Kaihatu ${ }^{2}$
}

\begin{abstract}
Desalination is a significant source of potable water to the Persian Gulf (simply, the Gulf) region. At present, the Gulf countries are the biggest users of seawater desalination with over $50 \%$ of the world's installed capacity. While, as ground- and surface water sources may become scarce or endangered in the Middle East and North Africa (MENA) region, water desalination activities are expected to continue growing in quantity and capacity, particularly in the Gulf region. However, it is not yet clear what the environmental effects are of increased brine discharge to the nearshore and offshore environments, as reliance on mass exchange through the Strait of Hormuz may be insufficient for necessary levels of flushing. To study this, a three-dimensional characterization of the Gulf has been developed using the Delft3D-FLOW hydrodynamic model. This model was used to obtain the hydrodynamics and flow transporting characteristics in the Gulf. In addition to meteorological and oceanographic forcing, the seasonal discharges of four major rivers and numerous desalination plants in the Gulf region were considered to the modeling system. Field measurements from Texas A\&M University at Galveston (TAMUG) Microstructure Group in 2013 provided the validation for the model. The maximum $4.21 \mathrm{ppt}$ and $4.32^{\circ} \mathrm{C}$ increases in salinity and temperature, respectively, due to the brine discharge of desalination were obtained at the adjacent area to six desalination plants in the Gulf.
\end{abstract}

Keywords: desalination; salinity; hydrodynamics; environmental effects

\section{INTRODUCTION}

\section{Environment of the Gulf}

The Persian Gulf, shown in Figure 1, is a long (approximately, $1000 \mathrm{~km}$ in length) and narrow (550 km in width) body of water in Western Asia (Emery 1956), bordered primarily by Iran, Iraq, Kuwait, Qatar, Saudi Arabia and United Arab Emirates (UAE). It is a large inverse estuary with the Strait of Hormuz (a deep and narrow channel of about $56 \mathrm{~km}$ in width) as the only major connection to the Gulf and Indian Ocean. A unique feature of the wind forcing in this area is the Shamal, a strong

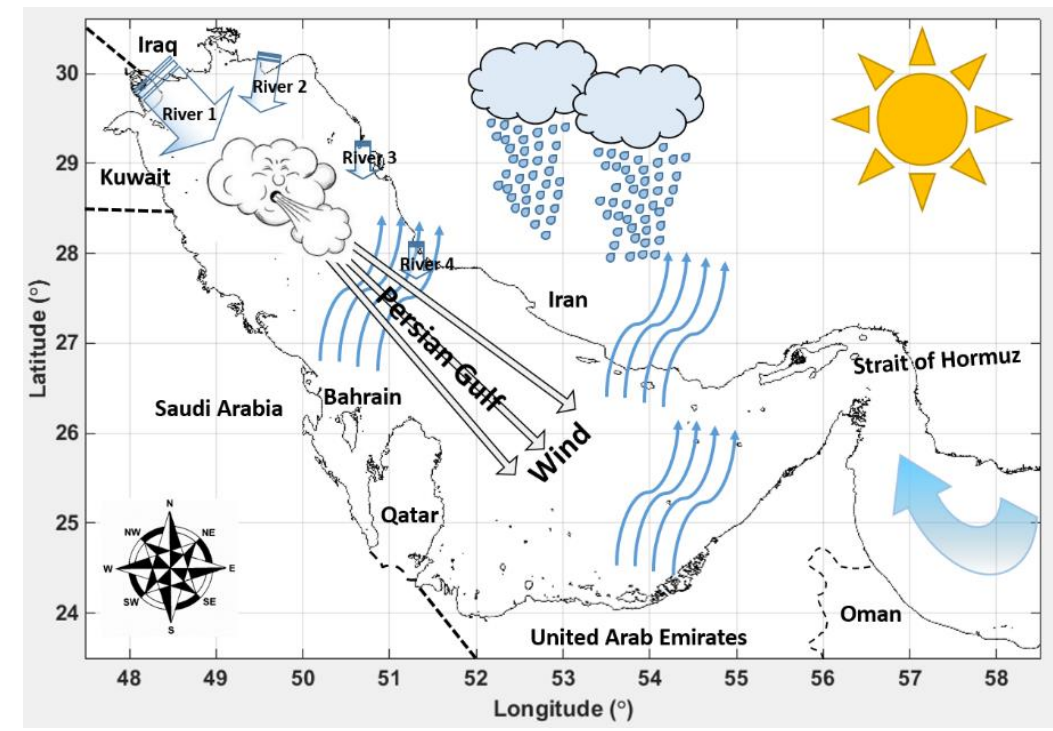

Figure 1. Schematic of oceanographic and climatological features in the Gulf.

northerly wind usually presents in summer and winter. The level of salinity in the Gulf can exceed 40 ppt in shallow and over $50 \mathrm{ppt}$ in limited areas, with large seasonal variation in temperature (Bower et al. 2000). The southern Gulf consists of a large shallow region with several islands, and is the site of intense evaporation (Reynolds 1993). In addition, the Gulf region experiences a mainly arid climate associated with desert conditions. The high evaporation, hot climate and strong wind events increase the hydrodynamic variability in the Gulf.

1 Zachry Department of Civil Engineering, Texas A\&M University, 3136 TAMU, College Station, TX, 77843-3136, U.S.

2 Zachry Department of Civil Engineering, Texas A\&M University, 3136 TAMU, College Station, TX, 77843-3136, U.S. 


\section{Background of Desalination}

Desalination is the removal process of salt and other minerals from seawater and brackish water to create potable water for human consumption as well as for agricultural and industrial uses (Elimelech and Phillip, 2011). Desalination is used in 133 countries and a total of 13,600 plants have either been installed or planned since 2000, based on the IDA 2000 Worldwide Desalting Plants Inventory Report (No. 16, Wangnick, 2000). According to the MENA regional water outlook (Verdier et al. 2011), approximately 2,800 desalination plants produce $27 \mathrm{Mm}^{3} /$ day of fresh water in the MENA region. As shown in Figure 2, the Gulf Cooperation Council (GCC) countries are the largest users of desalinated

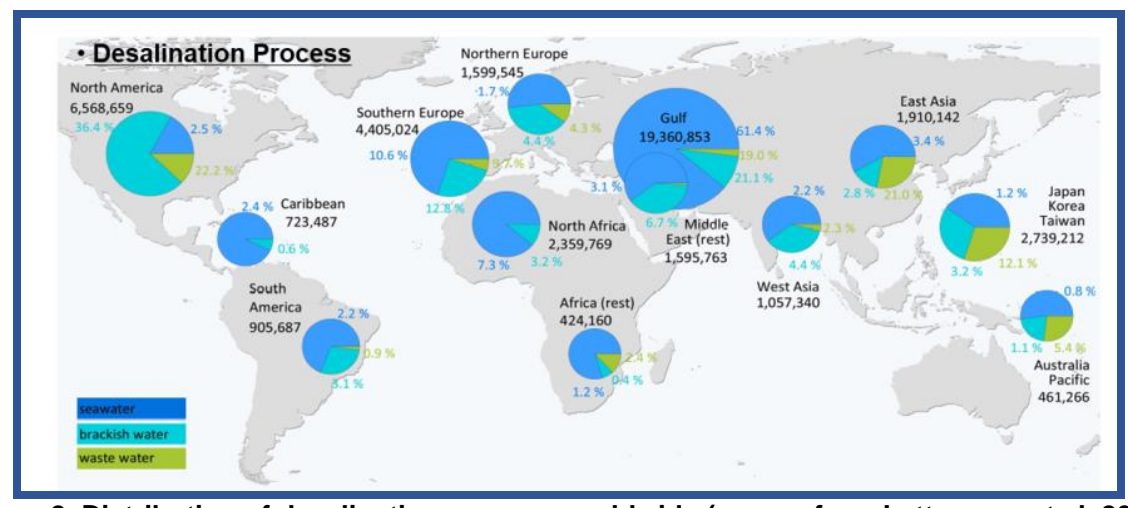

Figure 2. Distribution of desalination process worldwide (source from Lattemann et al. 2010).

fresh water, with over 50\% of the world's installed capacity (Awerbuch 1998). Desalination has increased in the wake of rapid industrialization, along with production associated with the vast crude oil and gas reserves in the Gulf (Al-Faris, 2002). As the establishment of the petrochemical industry in the Gulf region has increased the standard of living and population in each Gulf country for decades (UN, 2017 as shown in Figure 3), this growth also causes high water demand. Desalination is a significant source of potable water to the Gulf region, and it is not yet clear what the environmental effects are of increased brine discharge to the Gulf, as reliance on mass exchange through the Strait of

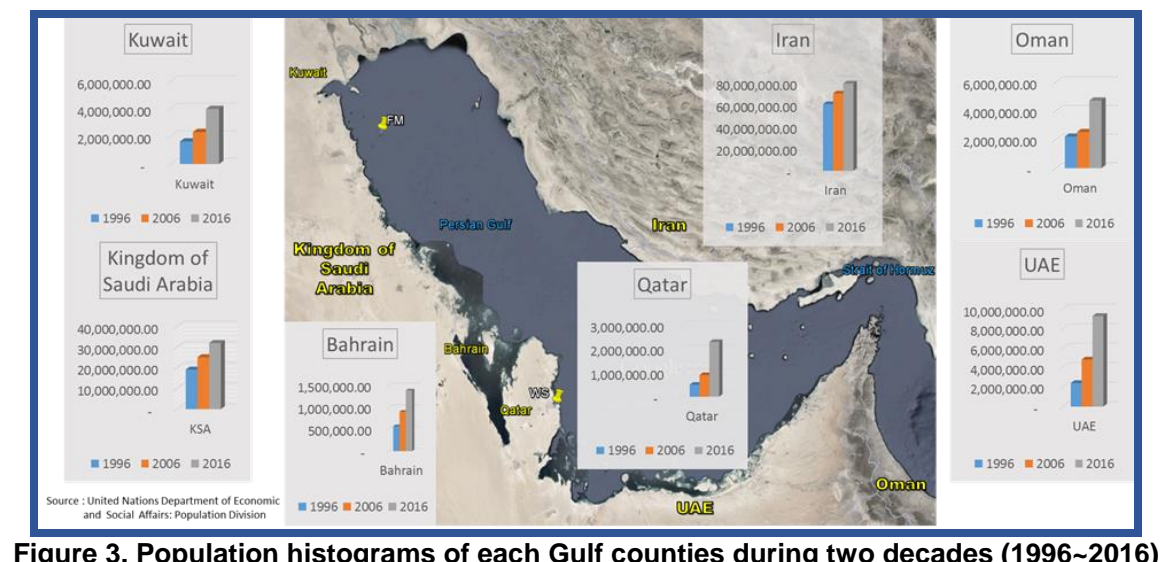

Hormuz may be insufficient for necessary levels of flushing. Immerzeel et al. (2011) suggest that the resources of natural surface and ground water will be significantly reduced on future availability due to the effect of climate change. In addition, Hopner (1999) and Schiffler (2004) have pointed out the need to engage in long-term planning and management for desalination process. The desalination process provides a dependable solution to supply fresh water in the Gulf region, and is a means of production best suited for the arid climate of the Gulf (Al Barwani and Purnama 2008). Continued growth of desalination capacity is presently ongoing and will be further extended (GWI 2010).

While, desalination technology has no doubt aided in the development of the Gulf countries, there are marine and environmental concerns, as intake and outfall processes of desalination have potential to deteriorate the marine ecosystem (Cooley et al. 2006). Recent studies have illustrated near field predictions of brine discharge which demonstrate that desalination can have environmental impacts. Bleninger (2006) discussed the effects of the contaminant mass flux using the hydrodynamic model 
Delft3D linked with CORnell MIXing Zone expert system (CORMIX), and examined coastal water quality problems regarding energy consumption and land use (Bleninger and Jirka, 2010). Lattemann and Hopner (2008) evaluated the overview of outfall discharge with two different type of desalination processes (RO, MSF), and discussed the potential impacts of this process on the salinity of the Gulf using a mathematical model (Al Barwani and Purnama, 2008). The salinity variations due to the desalination process were evaluated by using the collected data (Uddin 2014), leading to a hypothesis that increased salinity is able to destroy the ecosystem in the northern Gulf. Mickley (1995) also showed increases of salinity and temperature $\left(15 \%\right.$ and $5 \sim 15^{\circ} \mathrm{C}$ respectively) over ambient seawater conditions. In addition, there are various studies regarding salinity increases due to desalination; Purnama et al. (2005) have suggested salinity increase of the order of $0.06 \mathrm{ppt}$ due to desalination plant operations (Al Jubail in Saudi Arabia), with peak salinity increases as high as 2 ppt (Verdier et al., 2011); Other studies show 2 ppt increase at Canary Island desalination plants (Talavera and Ruiz, 2001), 4 ppt increases from various outlets in Florida (Einav et al. 2002), and increase of about 0.005 0.01 ppt (Dawoud and Al Mulla, 2012) at a vicinity of desalination plants in the Gulf. Recently, a similar Gulf study using the Delft3D-FLOW (Deltares, 2011) model for the northern Gulf region was conducted by Alosari and Pokavanich (2017). They investigated the seasonal hydrodynamic features of the northern Gulf. The discharge from four rivers and five desalination plants with constant outfall rates were applied to the model; these inputs led to local effects of about 2 ppt increase in salinity and $3^{\circ} \mathrm{C}$ in temperature due to desalination discharge. It is clear that desalination processes can affect the security of water supplies in the Gulf area as well as environmental aspects (Sheppard et al. 2010).

In this study, we use the validated model, incorporating spatially and temporally detailed input information such as transport boundary, various oceanographical and meteorological conditions of the Gulf region over a finer grid. In addition to discharge from the four major rivers, all available time series data of desalination process in the Gulf area were applied to the modeling system. Furthermore, the parameterization of "in-out" (intake-outfall) desalination processes was used to properly simulate the desalination process.

The Gulf has unique meteorological and oceanographic processes which respond directly to climate change (IPCC Fifth Assessment Report 2014). These changes can have significant impacts on predictions and evaluations of the model results driven by desalination, and additional modeling studies will investigate the effects of climate change with future desalination process. These serve as motivation to investigate the environmental effects from the brine discharge of desalination in this study. It can be also useful for prospective study to obtain the effects of global climate change and future desalination process in the Gulf region.

\section{MODELING SYSTEM}

\section{Model Description}

The hydrodynamic model Delft3D-FLOW (Deltares, 2011), based on the non-linear shallow water equation in two or three dimensions, is used to investigate the environmental effects of seawater desalination in the Gulf. It is a spherical rectangular grid with a resolution of $0.03^{\circ} \times 0.03^{\circ}$ with ten vertical sigma-layers. Bathymetry from the General Bathymetric Chart of the Oceans (GEBCO, 2014) is adopted and one open sea boundary in the Gulf of Oman is closed at $57.9^{\circ} \mathrm{E}$ and $23.8^{\circ} \mathrm{N}$ to $25.6^{\circ} \mathrm{N}$, but water level open boundary condition is used and forced by the tidal astronomic constituents from the TPXO 7.2 Global Inverse Tide Model (Appx.1 Egbert and Erofeeva 2002). In addition, the offshore transport boundary conditions were obtained from Myocean model (Appx.2, Product of global reanalysis phys_001_011,2016, http://marinecopernicus.eu/). The wind input is based on the temporally and spatially varying dataset from the National Centers for Environmental Prediction (NCEP) Climate Forecast System Reanalysis (CFSR, Saha et al. 2010 and 2012). A monthly mean climatological forcing for certain parameters, such as air temperature $\left({ }^{\circ} \mathrm{C}\right)$, cloud cover $(\%)$, relative humidity $(\%)$, precipitation and evaporation rate $(\mathrm{mm} / \mathrm{hr})$, was applied to the modeling system, using 54 years (1948 2002) of National Oceanic and Atmospheric Administration (NOAA) data. In addition to global climatological and oceanographic forcing, the seasonal discharge of four major rivers and numerous desalination plants in the Gulf region were input to the model.

\section{Model Validation}

The model applied a 4- year (2009 2012) spin-up to ensure that hydrodynamic features reached a dynamic equilibrium. Figure 4 shows the sample results of model spin-up in the northern, middle and southern Gulf using the salinity and temperature. The Microstructure Group at Texas A\&M University 
at Galveston (TAMUG) provided measurements of current velocities and temperature at the bottom, located at $28.85^{\circ}, 48.79^{\circ}$ (Lat/Lon) offshore of Kuwait (shown in Figure 4), taken during 2013. Wind data from the Doha International Airport weather station were used for wind validation. The time frame of field data was from January $17^{\text {th }}$ to April $22^{\text {nd }} 2013$, and the refined index of agreement (Eq. 1, Wilmott et al. 2012) was applied to quantify the fit to field data.

$$
d_{r}=1-\frac{\sum_{i=1}^{n}\left|\left(P_{i}-\bar{O}\right)-\left(O_{i}-\bar{O}\right)\right|}{\sum_{i=1}^{n}\left(\left|O_{i}-\bar{O}\right|+\left|O_{i}-\bar{O}\right|\right)}=1-\frac{\sum_{i=1}^{n}\left|P_{i}-O_{i}\right|}{2 \times \sum_{i=1}^{n}\left(\left|O_{i}-\bar{O}\right|\right)}
$$

where $n=$ total number of input data; $P_{i}=$ predicted model value; $O_{i}=$ observed field value; $d_{r}=$ the sum of the magnitude for the difference between the modeled and observed deviations against the observed mean relative to the sum of the magnitudes of the ideal-model $\left(P_{i}=O_{i}\right)$. Three components bottom temperature, currents and winds - were used in model validation.
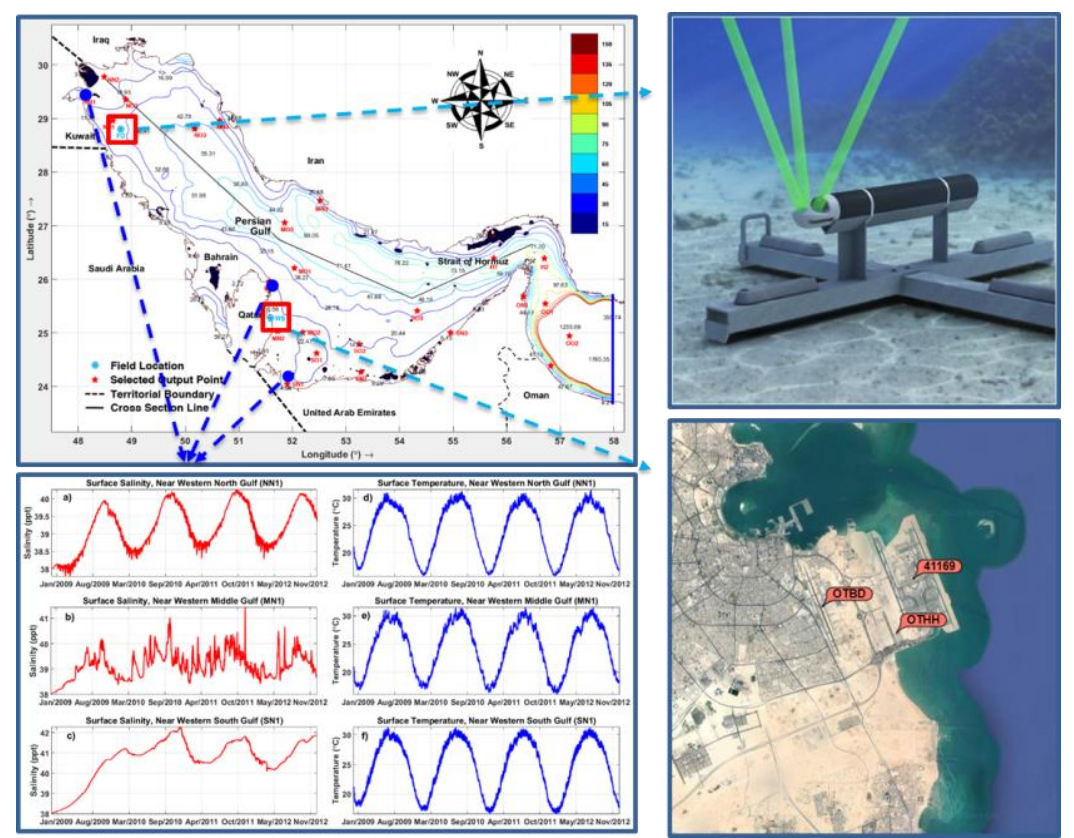

Figure 4. (from top left, clockwise) The location map of field measurement; ADCP bottom framed field deployment for the currents and bottom temperature at the offshore of Kuwait; Doha international airport weather station for historic wind data; Example of model spin-up results in the Gulf.

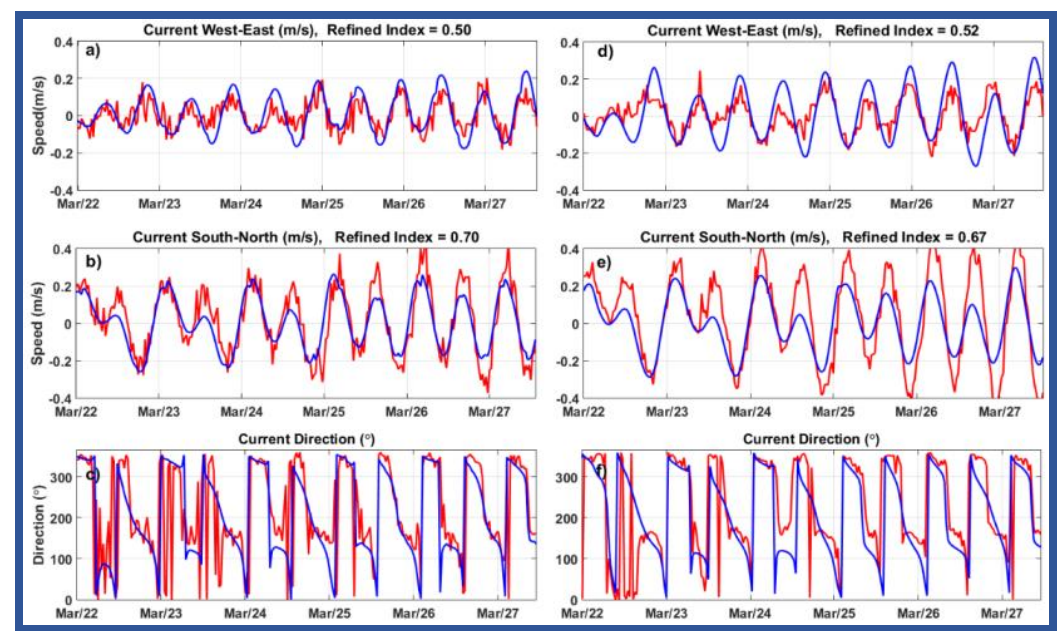

Figure 5. Validations of current simulation $\left(\mathrm{m} / \mathrm{s},{ }^{\circ}\right)$ : Observed current in red and predicted results in blue. (Left panel) Current speeds and direction at the bottom layer; (Right panel) Current speeds and direction at the middle layer. 
The currents at the bottom and middle of model layers were used to validate against the field measurement. Figure 5 shows the comparisons of the current speed and direction for each layer, and the refined index was used to quantify the degree of fitting to the field current curves. The resulting values of refined index were estimated over entire time of validation, but Figure 5 shows the comparisons over a six-day period. The model shows overestimation of currents in 'West-East' direction for each layer, whereas the currents of 'South-North' direction were underestimated at both layers. The relatively low spatial and temporal resolutions of the model generated the rough computed depths in the entire domain, and the slight differences of current speeds were probably an inevitable consequence. Moreover, the uniform tidal force at the boundary and bottom roughness in the entire Gulf likely produced phase lags in the comparisons of the current speeds and directions. Despite this, reasonable refined indices of agreement of 0.5 and 0.7 at the bottom and 0.49 and 0.67 at the middle layer were obtained for 'West-East' and 'South-North' direction, respectively.

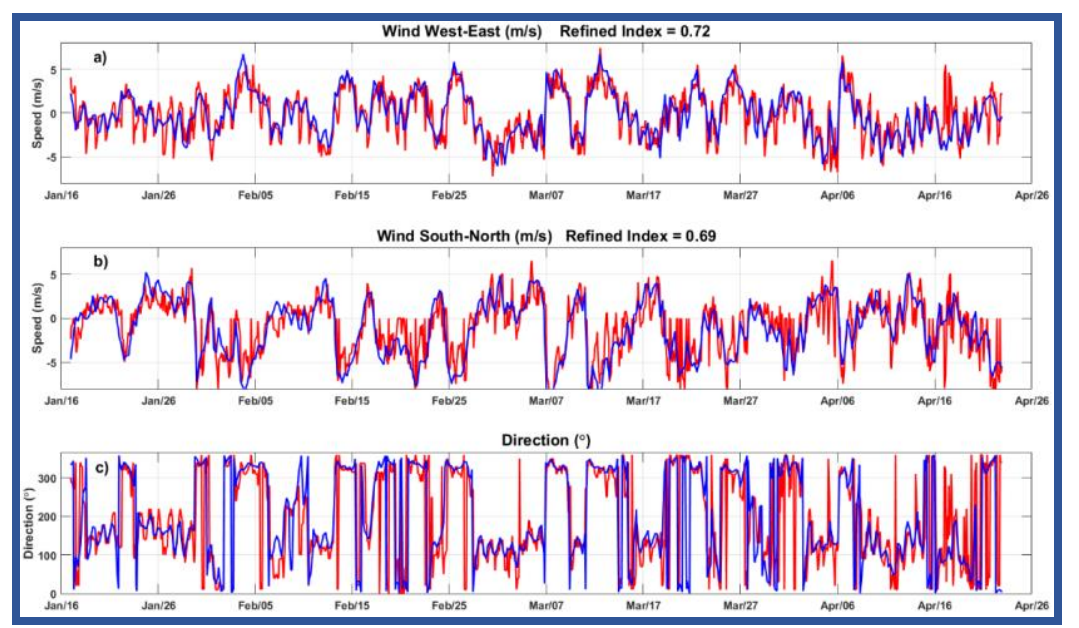

Figure 6. Validations of wind simulation $\left(\mathrm{m} / \mathrm{s},{ }^{\circ}\right)$ : Observed wind speeds and direction in red and predicted results in blue.

NCEP/CFSR reanalysis winds (Saha et al. 2012) were evaluated with the observed wind data at Doha International Airport weather station $\left(25.26^{\circ} \mathrm{N}, 51.57^{\circ} \mathrm{E}, 10 \mathrm{~m}\right.$ elevation). The six hourly winds of reanalysis data with $0.5^{\circ} \times 0.5^{\circ}$ spatial resolution were applied for the Gulf region. Figure 6 shows the comparison of wind speeds and directions. The wind speeds of 'West-East' and 'South-North' are estimated with the refined index 0.72 and 0.69 , respectively. Some differences are shown at high and low peaks of wind speeds due to different spatial and temporal resolutions, and a small phase lag appears in the corresponding direction. However, the input-winds are in good agreement with field wind data at the airport weather station.

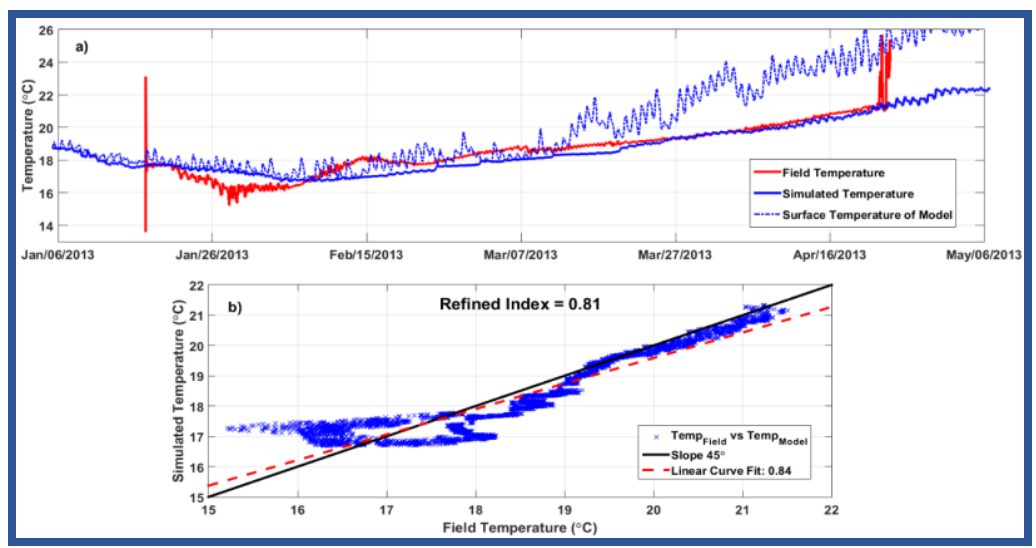

Figure 7. Validations of temperature simulation $\left({ }^{\circ} \mathrm{C}\right)$ : a) Comparison of predicted surface (dashed blue line) and bottom (solid blue line) temperatures with the observed temperature (in red). b) Predicted bottom temperature (y-axis) vs observed bottom temperature (x-axis). 
Temperature was measured at the bottom, about 25-26 m water depth at the field location. The instrument calibration was conducted during the first 24 hour period, while the large fluctuations near the end of the data are a consequence of instrument removal. Figure 7 shows the comparisons between the measured and predicted temperatures. Although the modeled temperature was somewhat overestimated in the early stage of the comparison, it yielded a refined index of 0.81 , indicative of a small model-data difference for the entire range of temperature variation. Table 1 presents a summary of the refined index of agreement for the model performance.

\begin{tabular}{|c|c|c|c|c|c|c|c|}
\hline \multicolumn{9}{|c|}{ Table 1. A Summary of refined index of agreement in the model validation. } \\
\hline \multirow{2}{*}{ Temperature } & \multicolumn{2}{c|}{$\begin{array}{c}\text { Current Speed } \\
\text { (Bottom Layer) }\end{array}$} & \multicolumn{2}{c|}{$\begin{array}{c}\text { Current Speed } \\
\text { (Middle Layer) }\end{array}$} & \multicolumn{2}{c|}{ Wind Speed } \\
\cline { 3 - 8 } & & $\mathrm{U}$ & $\mathrm{V}$ & $\mathrm{U}$ & $\mathrm{V}$ & $\mathrm{U}$ & $\mathrm{V}$ \\
\hline R.I & 0.81 & 0.50 & 0.70 & 0.52 & 0.67 & 0.72 & 0.69 \\
\hline
\end{tabular}

\section{Desalination Process}

Three different technologies - Multi-Stage Flash (MSF), Multi-Effect Distillation (MED) and Reverse Osmosis (RO) - account for $63 \%, 16 \%$ and $21 \%$ of all desalination operations, respectively (Lattemann et al. 2013) and are most dominant desalination techniques in the Gulf. The strategy of this study is to employ the validated model and investigate the influx-efflux (or "in-out") water cycle of desalination process for three different types of desalination technology. The modeling system of desalination process is based on several assumptions. There are some issues for incorporating in-out discharge system in the Delft3D-FLOW model, which compel us to use the following assumptions:

- Information on in-out plant's discharge points is scarce. While the actual locations of the intake and discharge points depend on geological conditions and system efficiency (Bleninger and Jirka 2010), it is likely that the distance between these two points is not less than $2 \sim 3 \mathrm{~km}$. Due to the grid resolution, it is assumed that the in-out points are at the same grid point in the model.

- It is unclear when the plants open and close the water gate at the in-out discharge point. Thus, it is assumed that plants are continuously operating during the simulation time period.

- It is also difficult to define the ambient water conditions in the vicinity of the intake points because desalination data, such as the salinity, temperature and flow rate of in-out discharge, are very scarce. Although the "Off Desalination" model run can help the guidance for initial conditions of ambient water, it is not useful to estimate the subsequent ambient conditions from the intake points, as these ambient conditions are likely affected by the effluent of continued desalination discharge. In contrast, the high saline water at the outfall discharge must be specified according to values of salinity and temperature and flow rates of intake water characteristics. The relationship (as shown in Table 2, Elhakeem, 2014) of increases in salinity and temperature at discharge can be used to consider the salinity and temperature of outfall effluent. However, the estimation the ambient water characteristics near intake point, such as salinity and temperature, is still needed to properly simulate the in-out discharge process. To cope with this issue, we estimate the water characteristics of salinity and temperature for intake water as a series of month-by-month model runs. The monthly mean intake water characteristics were assumed to be a source of desalination process. This approximate method led to the averaged conditions of ambient water at the intake point.

\begin{tabular}{|c|c|c|}
\hline \multicolumn{3}{|c|}{ Table 2. Increase of salinity and temperature at the discharge (Elhakeem, 2014). } \\
\hline Type & $\begin{array}{c}\text { Increase of salinity (ppt) } \\
\text { to ambient condition }\end{array}$ & $\begin{array}{c}\text { Increase of temperature }\left({ }^{\circ} \mathrm{C}\right) \\
\text { to ambient condition }\end{array}$ \\
\hline MSF & 10 & 10 \\
MED & 15 & 10 \\
RO & 44.8 & 1 \\
\hline
\end{tabular}

- The discharge of each of these plants is designated in a distributed vertical layer in the model. This is done according to the tendencies of the MSF and MED plants with the positive (from the surface) buoyant plumes, and the RO plant with negative (from the bottom) buoyant plumes (Bleninger et al. 2010). By specifying the $\sigma$-layer number of discharge point in the water column, the concentrations with the discharge rate are released to the near-field 
environment. Based on the type of plant, the vertical location of the discharge point is specified via the $\sigma$-layer number of the vertical grid.

A model has been tested to obtain rapid and useful predictions of effects of desalination discharge in the Gulf, and then developed the model to investigate the environmental effects and hydrodynamic features due to the brine discharge, using the available data of desalination for the Gulf region.

\section{MODEL RESULTS}

A total of 76 desalination plants, as shown in Figure 8, were applied to the modeling system (listed in Appx.3). Three different types of desalination and temporally varying brine discharge with salinity and temperature are employed for desalination process of the model, based on primary desalination data from Elhakeem (2014).

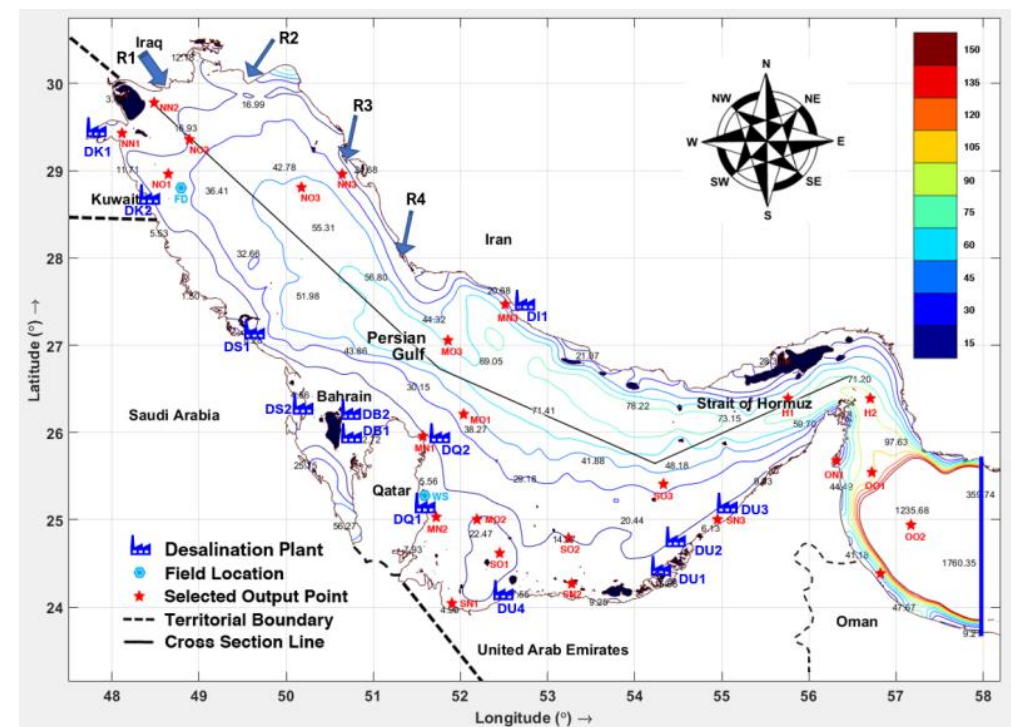

Figure 8. Location map of desalination plants in the Gulf with the Gulf bathymetry.

Figures 9 and 10 display the differences ('On Desalination' minus 'Off Desalination') of monthly mean surface salinity and bottom temperature, respectively, of the entire Gulf during the 12 year interval (2004 2016). The salinity increase, about 0.2 ppt and over 1 ppt in maximum, were obtained along the Gulf coast. In particular, increased levels of salinity appeared consistently near the southern Qatari coast, Bahrain and Kuwait Bay, due to the impeded circulation in these regions. Additionally, there are locally increased levels of temperature, with $0.2 \sim 1.0^{\circ} \mathrm{C}$ increases in the areas adjacent to the desalination discharge in Kuwait Bay and the nearshore area of UAE. It is interesting to note that there

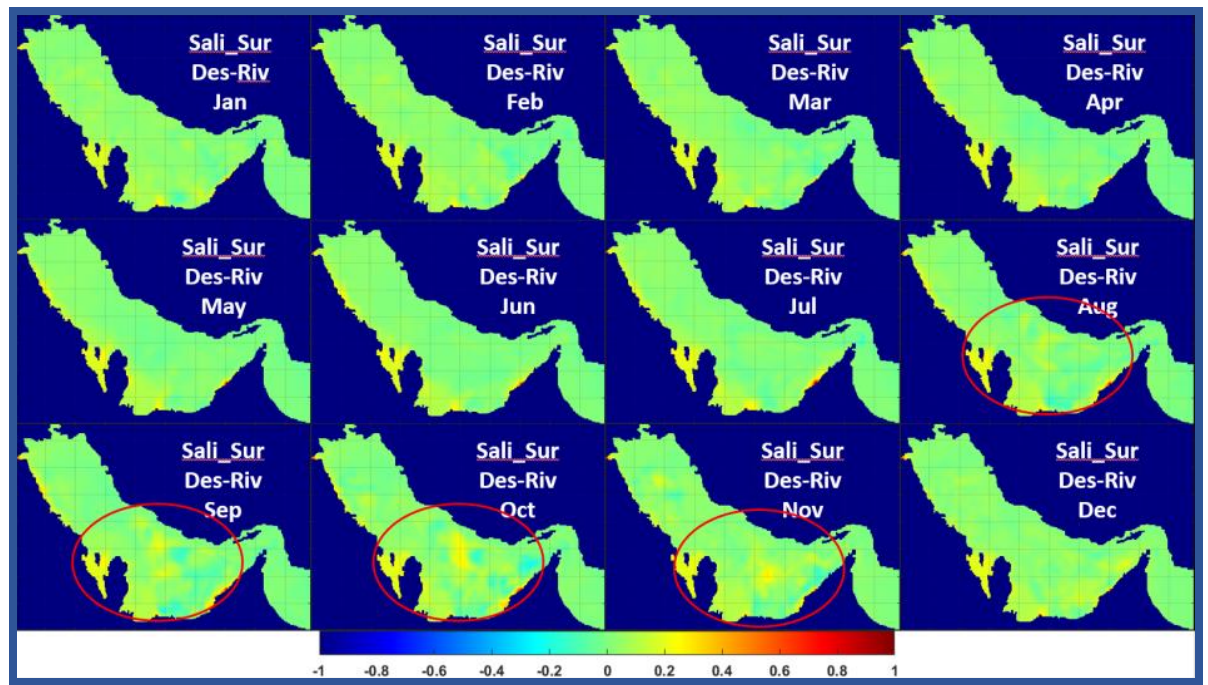

Figure 9. Differences of monthly mean surface salinity (ppt) for entire Gulf. 
are notable increases of mean surface salinity and bottom temperature between August and November during 12 years, as shown in the red circles of Figure 9 and 10. There were no discharge pipes of desalination plants in the red-circled areas, but various physical processes may act on the salinity and temperature fields in the middle Gulf area as a result of the increases due to desalination. This is in line with the findings of Morelissen et al. (2016), who provided the depictions of the Gulf circulation, pollutant tracer and spreading of harmful algae blooms and oil spills in the Gulf area via satellite images. These images show that the tracer residence time is high in the vicinity around the red circle in Figure 9 and 10, likely due to the Gulf circulation, evaporation, wind driven thermohaline process and surface water inflows from the Indian Ocean. The specific times of these occurrences do not appear in figures by Morelissen et al. (2016), but it is likely that the high rates of evaporation during summer to fall lead to increased salinity and temperature due to the effect of brine discharge.

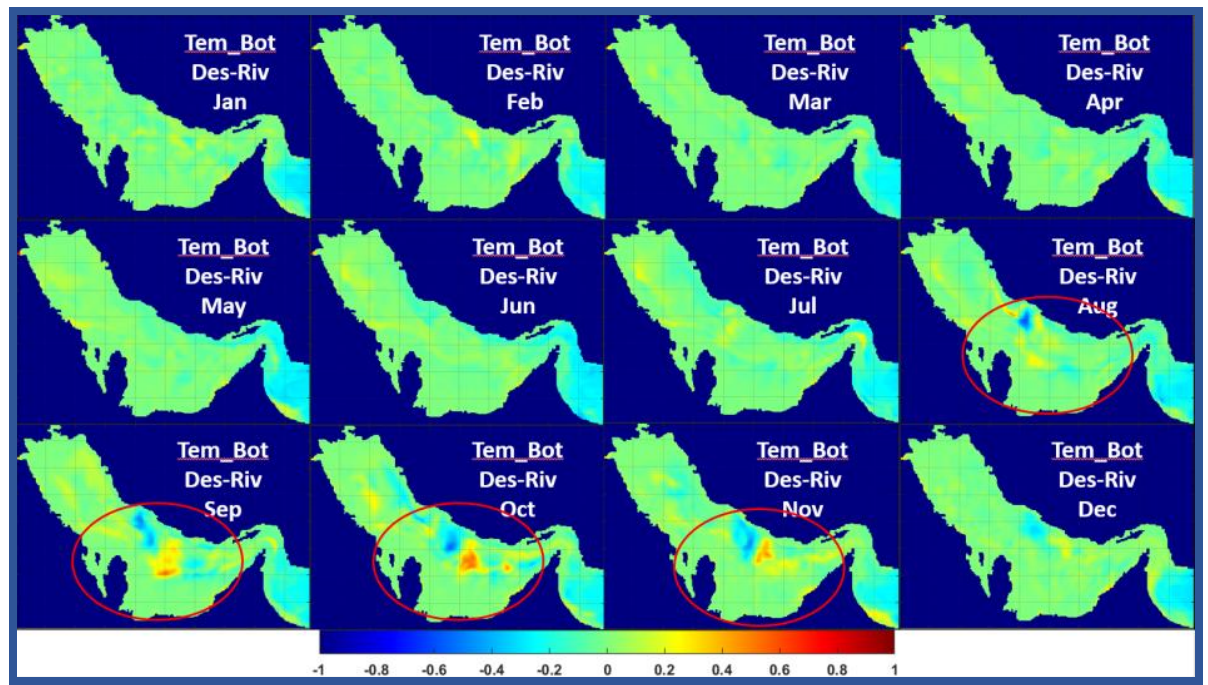

Figure 10. Differences of monthly mean bottom temperature $\left({ }^{\circ} \mathrm{C}\right)$ for entire Gulf.

Seasonal characteristics of salinity and temperature were also obtained from the model results. These are likely to be attributed to the unique meteorological and oceanographic features. The hydrodynamic characteristics in the Gulf show high variability forced by the evaporation and precipitation rate (Premchand et al. 1986; Ahmad and Sultan 1991; Mosaddad and Delphi 2013). The positive 'Evaporation Minus Precipitation" (EMP) rate (Kumar and Prasad 1999; Xue and Eltahir 2015; Pous et al. 2015) for a long-term period may be attributed to the high potential of warm and saline water environment in the Gulf region. In addition, the strong seasonal winds, during Shamal events, may

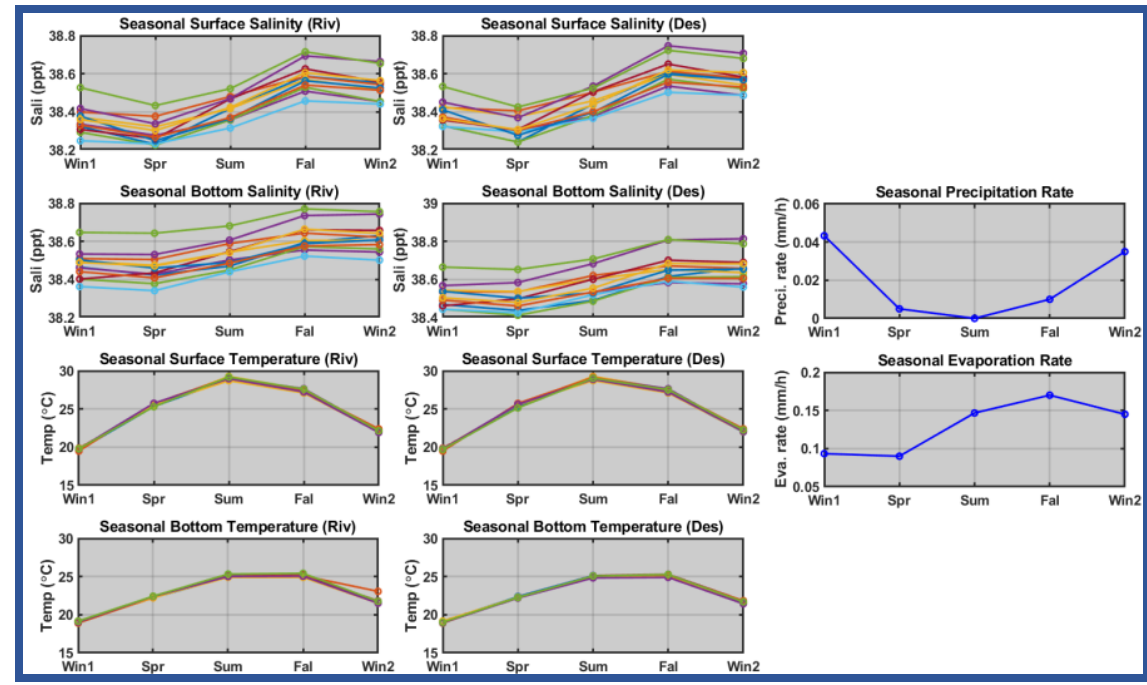

Figure 11. Variations of seasonal mean salinity (ppt) and temperature $\left({ }^{\circ} \mathrm{C}\right)$ during 2004 2016, compared with precipitation and evaporation rates $(\mathrm{mm} / \mathrm{hr})$. 
affect the vertical water mixing and thermohaline structure, likely due to the surface wind force (Reynolds 1993). Figure 11 shows the variations of seasonal mean salinity and temperature, compared with the input-conditions of the precipitation rate (54 years, 1948 2002, of National Oceanic and Atmospheric Administration (NOAA) data) and evaporation rate (Elhakeem et al. 2015). The seasonal variations of salinity are highly dependent on the input-evaporation rate, and the seasonal temperature is greatly affected by the input-precipitation. The annual mean evaporation rate of the Gulf has been variously estimated as $1.8 \mathrm{~m} / \mathrm{yr}$ (Kämpf and Sadrinsab, 2006), $2 \mathrm{~m} / \mathrm{yr}$ (Hastenrath and Lamb 1979; Meshal and Hassan, 1986;) and $2.09 \mathrm{~m} / \mathrm{yr}$ (Elhakeem et al. 2015), and the maximum rate of evaporation was found in the summer season (2.55 m/yr, Elhakeem et al. 2015). Privett (1959) estimated the annual evaporation rate, $1.44 \mathrm{~m} / \mathrm{yr}$, with the highest rate in winter, contrasting result to the recent studies (Sultan and Elghribi, 2002; ElNesr et al. 2011, etc.) which show the highest rate in summer. This study presents also the highest evaporation rate $2.57 \mathrm{~m} / \mathrm{yr}$ in summer, as shown in Table 3. In Figure 11, the levels of mean salinity in fall show slightly higher about 0.1 0.2 ppt than mean

\begin{tabular}{|c|c|c|}
\hline \multicolumn{3}{|c|}{ Table 3. Seasonal mean evaporation flux and rate from the model results. } \\
\hline Season & Evaporation Flux $\left(\mathrm{W} / \mathrm{m}^{2}\right)$ & Evaporation Rate $(\mathrm{m} / \mathrm{yr})$ \\
\hline Winter & 133.15 & 1.68 \\
Spring & 156.62 & 1.98 \\
Summer & 203.92 & 2.57 \\
Fall & 191.14 & 2.41 \\
Mean & 163.60 & 2.06 \\
\hline
\end{tabular}

salinity in summer and the levels of salinity in spring show typically lowest values. Correspondingly, Kämpf and Sadrinsab (2006) found that maximum salinities were obtained during October to December, while the minimum salinities were attained during March to May each year. Despite the evaporation rate in fall is slightly less than in summer, the relatively higher evaporation rate in the fall season can lead to highest level of salinity in the Gulf region, likely due to that the consecutive high evaporation rates during summer and fall strongly act on the Gulf environment.

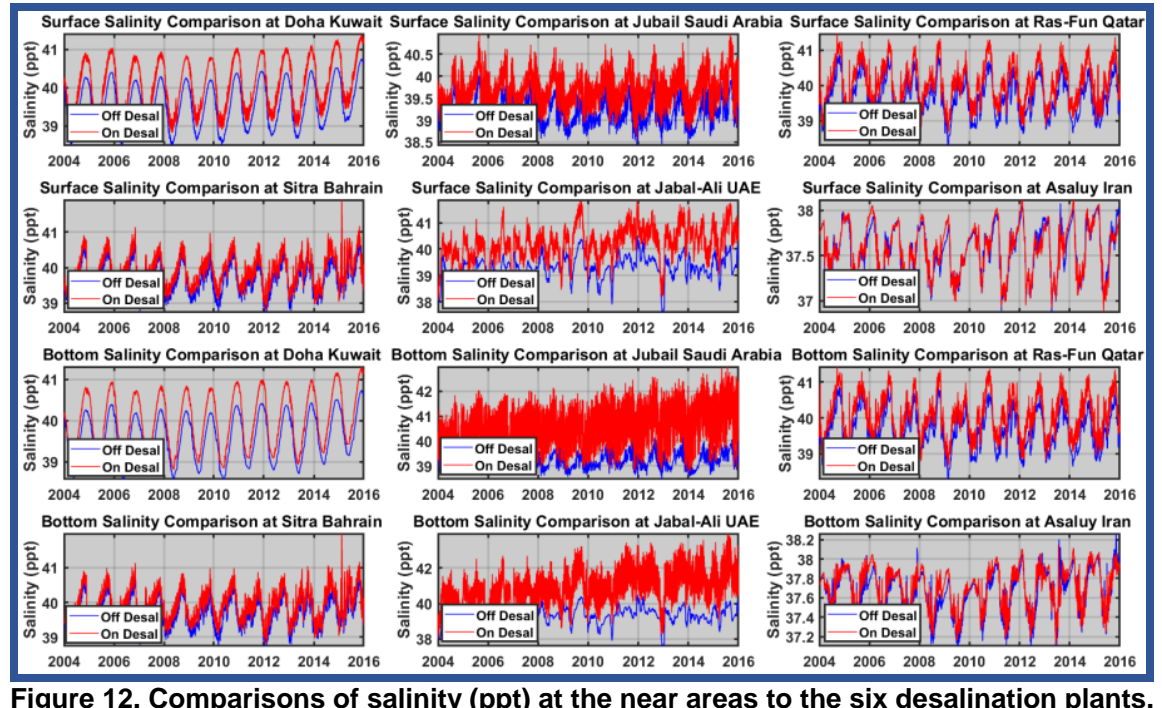

Figure 12. Comparisons of salinity (ppt) at the near areas to the six desalination plants.

\begin{tabular}{|c|c|c|c|c|}
\hline & Country & Plant (Location) & Max. $\Delta$ Salinity & Max. $\Delta$ Temperature \\
\hline 1 & Kuwait & Al-Doha (DK1) & 0.84 ppt (surface) & $2.74^{\circ} \mathrm{C}$ (Bottom) \\
\hline 2 & Saudi Arabia & Jubail (DS1) & $3.41 \mathrm{ppt}$ (Bottom) & $1.94^{\circ} \mathrm{C}$ (Bottom) \\
\hline 3 & Qatar & Ras Funats (DQ1) & 1.16 ppt (Surface) & $0.86^{\circ} \mathrm{C}$ (Bottom) \\
\hline 4 & Bahrain & Sitra (DB1) & 0.88 ppt (Bottom) & $0.48^{\circ} \mathrm{C}$ (Bottom) \\
\hline 5 & UAE & JabalAli (DU3) & $4.21 \mathrm{ppt}$ (Bottom) & $1.60^{\circ} \mathrm{C}$ (Surface) \\
\hline 6 & Iran & Asaluy (DI1) & 0.43 ppt (Bottom) & $4.32^{\circ} \mathrm{C}$ (Bottom) \\
\hline
\end{tabular}


Figure 12 shows the comparisons of salinity to investigate the effects of brine discharge at the adjacent areas to the desalination plants. As shown in Table 4 and Figure 12, the six major desalination plants of six Gulf countries were used to compare the variations of salinity and temperature. The maximum 4.21 ppt increase of bottom salinity and $1.6^{\circ} \mathrm{C}$ increase of surface temperature were resulted in Ali-Jabal desalination plant of UAE. The influence of brine discharge is mainly localized within $2 \sim 3 \mathrm{~km}$ from the discharge location, and unaffected in the offshore areas, likely due to more dilution.

Studies showing the effect of desalination plants discharge of high saline water on the Gulf environment and marine ecosystem, are somewhat scarce for the Gulf region. According to several studies concerning the negative impacts of the desalination discharge (Purnama et al., 2005, Dupavillon and Gillander, 2009), the increased levels of salinity and temperature influence fish growth (Boeuf and Payan, 2001) and eggs production (Dana and Lenz, 1986) in marine ecology. However, the mangroves are sensitive to salinity changes between inland freshwater and seawater. If the seawater is too saline condition by the desalination discharge, their growth can be seriously affected (Burchett et al, 1989). The corals are also sensitive to the high temperature (Brown, 1997), so that increased high level of temperature may be deadly impact on the coral reef. In addition, the mollusks, like cuttlefish inhabiting the Gulf area (Amini Yekta et al. 2014), may be reduced in their size and weight by the 3 ppt increase, and their survival affected by a 6 ppt increase (Dupavillon and Gillanders 2009). The desalination process has caused deleterious effects on the marine environment due to the vast amounts of high saline water from the plants' discharge, and it has been clearly demonstrated through various studies.

\section{CONCLUSION AND DISCUSSION}

The growth of population and industry in the Gulf has led to significant development of desalination processes under the arid climate with high evaporation rate. Desalination has been developed to meet various growing water demands, such as potable water for human consumption, agricultural and industrial uses, along the Gulf coast. As a result, an assessment of environmental impact due to the effect of high saline brine discharge is warranted. We have developed the desalination model to investigate the environmental effects of plants' discharge, using the hydrodynamic model, Delft3D-FLOW. Using the validated model including three-dimensional temporally varying climatological and oceanographic conditions over a finer model grid, several assumptions on desalination process were additionally applied to this study.

Figures 9 and 10 show the spatial results of monthly mean variations of salinity and temperature by desalination discharge during the 12 years. Increased levels of salinity appeared constantly across entire Gulf, but there are locally increased levels of temperature, with $0.2 \sim 1.0^{\circ} \mathrm{C}$ in the vicinity of the desalination plants. In addition, the seasonal characteristics of salinity and temperature were obtained from the model results. The seasonal mean salinity and temperature were strongly affected by inputevaporation and precipitation conditions, respectively. The highest level of salinity was seen in fall due to the effect of consecutive high evaporation rate during from summer to fall, which strongly influence the Gulf environment. The evaporation rate in fall is slightly less than in summer, but its effect is more likely to persist through summer to fall. The maximum $4.21 \mathrm{ppt}$ increases in salinity and $4.32{ }^{\circ} \mathrm{C}$ in temperature due to the brine discharge of desalination were obtained at the adjacent area to desalination plant. These substantial changes response to the desalination have a high potential to deteriorate the marine ecosystem. It has been reported that the increases of salinity and temperature influence negatively fish growth (Boeuf and Payan, 2001) and eggs production (Dana and Lenz, 1986) in marine ecology. As a result, the mollusks, fish and seagrass living in the Gulf are significantly sensitive to the changes of salinity and temperature (Amini Yekta et al., 2014, Dupavillon and Gillanders 2009).

A more comprehensive approach to assess high risk (Hart et al. 2003) of salinity and temperature increases is required for the marine ecosystem. Because of significant reduction of surface- and groundwater resources due to the climate change in the future (Immerzeel et al. 2011), the high reliance on desalination in the Gulf region will be facilitated. A modeling effort would be required to incorporate the climate change response to the climatological and oceanographic conditions with future desalination process in the Gulf for the total modeling system. The environmental impact assessment of desalination discharge with the effect of global climate change still remains a significant need for the Gulf study. In addition, the flushing (tracer residence) time and dilution problems driven by 
desalination process in the Gulf region will be discussed and estimated with the physical and hydrodynamic processes in the Gulf environment.

\section{ACKNOWLEDGMENTS}

This work was supported by the Qatar National Research Fund (QNRF, a member of the Qatar Foundation) under Grant NPRP 7-660-1-124.

\section{APPENDIX}

\begin{tabular}{|c|c|c|c|c|}
\hline \multicolumn{5}{|c|}{ Appx 1. Tidal astronomic constituents at open boundary } \\
\hline \multicolumn{3}{|c|}{$57.9^{\circ} \mathrm{E}, 23.8^{\circ} \mathrm{N}$} & \multicolumn{2}{|c|}{$57.9^{\circ} \mathrm{E}, 25.6^{\circ} \mathrm{N}$} \\
\hline Set & $\operatorname{Amp}(\mathrm{m})$ & Phase $\left({ }^{\circ}\right)$ & $\operatorname{Amp}(\mathrm{m})$ & Phase $\left({ }^{\circ}\right)$ \\
\hline $\mathrm{K}_{1}$ & 0.383 & 340.19 & 0.386 & 339.77 \\
\hline $\mathrm{O}_{1}$ & 0.201 & 347.16 & 0.206 & 342.36 \\
\hline $\mathrm{M}_{2}$ & 0.657 & 158.33 & 0.675 & 156.87 \\
\hline $\mathrm{S}_{2}$ & 0.253 & 189.92 & 0.261 & 189.13 \\
\hline
\end{tabular}

\begin{tabular}{|c|c|c|c|c|c|c|c|c|c|c|c|c|}
\hline \multicolumn{10}{|c|}{ Appx 2. Monthly mean climatological data from MyOcean model (example 2013). } \\
\hline Salinity & Jan & Feb & Mar & Apr & May & Jun & Jul & Aug & Sep & Oct & Nov & Dec \\
\hline Sur A & 36.57 & 36.55 & 36.58 & 36.64 & 36.71 & 36.79 & 36.83 & 36.78 & 36.70 & 36.70 & 36.77 & 36.76 \\
\hline Bot A & 36.33 & 36.44 & 36.50 & 36.57 & 36.65 & 36.68 & 36.67 & 36.65 & 36.71 & 36.72 & 36.59 & 36.41 \\
\hline Sur B & 36.54 & 36.52 & 36.53 & 36.60 & 36.65 & 36.64 & 36.59 & 36.50 & 36.51 & 36.7 & 36.75 & 36.69 \\
\hline Bot B & 36.22 & 36.31 & 36.39 & 36.47 & 36.50 & 36.53 & 36.69 & 36.82 & 36.79 & 36.66 & 36.48 & 36.34 \\
\hline Temperature & Jan & Feb & Mar & Apr & May & Jun & Jul & Aug & Sep & Oct & Nov & Dec \\
\hline Sur A & 25.03 & 23.93 & 24.42 & 26.00 & 27.78 & 29.69 & 30.9 & 30.37 & 30.26 & 30.86 & 29.76 & 27.24 \\
\hline Bot A & 19.63 & 20.14 & 20.70 & 20.42 & 19.67 & 19.72 & 19.70 & 19.2 & 19.21 & 19.03 & 19.24 & 19.63 \\
\hline Sur B & 24.77 & 23.46 & 23.54 & 24.76 & 26.59 & 29.34 & 31.45 & 31.54 & 30.75 & 30.21 & 28.61 & 26.20 \\
\hline Bot B & 19.37 & 20.19 & 20.51 & 20.18 & 19.19 & 18.90 & 19.59 & 19.66 & 19.42 & 18.39 & 18.66 & 20.11 \\
\hline
\end{tabular}

\begin{tabular}{|c|c|c|c|c|c|c|c|}
\hline \multicolumn{8}{|c|}{ Appx 3. A total of 76 desalination plants and mean brine discharge $\left(\mathrm{m}^{3} / \mathrm{s}\right)$} \\
\hline Country & Plant & Type & Outfall $(\mathrm{m} 3 / \mathrm{s})$ & Country & Plant & Type & Outfall $(\mathrm{m} 3 / \mathrm{s})$ \\
\hline \multirow{10}{*}{ Kuwait } & \multirow{3}{*}{ Ashwaiba } & MSF & 6.97 & & \multirow{3}{*}{ Tawila } & MSF & 35.74 \\
\hline & & MED & 1.55 & & & MED & 5.09 \\
\hline & & $\mathrm{RO}$ & 1.45 & & & $\mathrm{RO}$ & 1.64 \\
\hline & Doha-A & MSF & 24.10 & & \multirow{3}{*}{ JabalAli } & MSF & 75.15 \\
\hline & \multirow{2}{*}{ Ashwaikh } & MSF & 3.10 & & & MED & 3.82 \\
\hline & & $\mathrm{RO}$ & 1.45 & & & RO & 6.27 \\
\hline & \multirow{2}{*}{ Azour } & MSF & 18.20 & & \multirow{3}{*}{ Shuwaihat } & MSF & 32.00 \\
\hline & & MED & 1.09 & & & MED & 0.64 \\
\hline & \multirow{2}{*}{ Alsubia } & MSF & 14.36 & & & $\mathrm{RO}$ & 0.46 \\
\hline & & MED & 9.55 & & \multirow{3}{*}{ Quidfa } & MSF & 9.18 \\
\hline \multirow{7}{*}{$\begin{array}{l}\text { Saudi } \\
\text { Arabia }\end{array}$} & \multirow{2}{*}{ Khobar } & MSF & 18.86 & & & MED & 1.55 \\
\hline & & $\mathrm{RO}$ & 1.27 & & & $\mathrm{RO}$ & 5.00 \\
\hline & \multirow{3}{*}{ Jubail } & MSF & 52.06 & UAE & \multirow{2}{*}{$\begin{array}{l}\text { Quidfa- } \\
\text { Hybrid }\end{array}$} & MED & 6.18 \\
\hline & & MED & 17.27 & & & $\mathrm{RO}$ & 1.73 \\
\hline & & $\mathrm{RO}$ & 5.82 & & \multirow{3}{*}{ Layyah } & MSF & 5.75 \\
\hline & \multirow[b]{2}{*}{ Khafji } & MSF & 24.35 & & & MED & 2.45 \\
\hline & & $\mathrm{RO}$ & 3.20 & & & RO & 5.73 \\
\hline \multirow{9}{*}{ Bahrain } & Sitra & MSF & 4.63 & & \multirow{3}{*}{ Mirfa } & MSF & 5.64 \\
\hline & \multirow{2}{*}{ Ras Jarjoor } & $\mathrm{RO}$ & 0.73 & & & MED & 0.64 \\
\hline & & $\mathrm{RO}$ & 0.90 & & & $\mathrm{RO}$ & 0.10 \\
\hline & \multirow{3}{*}{ Alhidd } & MSF & 3.64 & & \multirow{2}{*}{ Ajman } & MED & 2.09 \\
\hline & & MED & 5.73 & & & $\mathrm{RO}$ & 2.73 \\
\hline & & $\mathrm{RO}$ & 2.36 & & \multirow{3}{*}{ Zawra } & MSF & 1.56 \\
\hline & Aldoor & RO & 0.50 & & & MED & 0.64 \\
\hline & \multirow{2}{*}{ Alba } & MED & 0.64 & & & RO & 1.45 \\
\hline & & $\mathrm{RO}$ & 0.27 & \multirow{7}{*}{ Iran } & \multirow{3}{*}{$\begin{array}{l}\text { Bandar } \\
\text { Abbas }\end{array}$} & MSF & 0.91 \\
\hline \multirow{6}{*}{ Qatar } & \multirow{3}{*}{ Ras Funats } & MSF & 26.00 & & & MED & 0.73 \\
\hline & & MED & 1.18 & & & $\mathrm{RO}$ & 1.18 \\
\hline & & $\mathrm{RO}$ & 0.73 & & \multirow{3}{*}{ Kishm } & MSF & 0.93 \\
\hline & & MSF & 14.45 & & & MED & 0.09 \\
\hline & Ras Lafan & MED & 15.09 & & & RO & 0.09 \\
\hline & & $\mathrm{RO}$ & 2.45 & & Bandar & MSF & 0.18 \\
\hline
\end{tabular}




\begin{tabular}{|c|c|c|c|c|c|c|}
\hline & Dukhan & MED & 1.20 & Lingeh & MED & 0.30 \\
\hline & Abu Samra & $\mathrm{RO}$ & 0.27 & Kish IsI & $\mathrm{RO}$ & 0.10 \\
\hline \multirow{4}{*}{ UAE } & Abudhabi & MSF & 4.35 & \multirow{2}{*}{ Asaluyeh } & MED & 1.55 \\
\hline & \multirow{3}{*}{ UmmAINar } & MSF & 33.98 & & $\mathrm{RO}$ & 1.56 \\
\hline & & MED & 0.64 & \multirow{2}{*}{ Bushehr } & MED & 0.10 \\
\hline & & $\mathrm{RO}$ & 1.27 & & $\mathrm{RO}$ & 0.27 \\
\hline
\end{tabular}

\section{REFERENCES}

Ahmad, F. and S.A.R. Sultan. 1991. Annual mean surface heat fluxes in the Arabian Gulf and the net heat transport through the Strait of Hormuz, Atmosphere-Ocean, 29:1, 54-61, DOI: 10.1080/07055900.1991.9649392.

Al Barwani H.H. and A. Purnama. 2008. Evaluating the effect of producing desalinated seawater on hypersaline Arabian Gulf. European Journal of Scientific Research, vol. 22, pp. 279 - 285.

Al-Faris, A.F. 2002. Public Expenditure and Economic Growth in the Gulf Cooperation Council Countries. Applied Economics 34.9: 1187-193.

Alosairi, Y. and T. Pokavanich. 2017. Seasonal circulation assessments of the northern Arabian Gulf. Mar. Pollut. Bull. 116: 270-290.

Amini Yekta, F., M. Jalili, F. Pourjomeh and H. Rezaei. 2014. Distribution of Molluscs in the Eastern Persian Gulf, PG-GOOS Cruise. Journal of the Persian Gulf (Marine Science), Vol. 5, No. 17. 37 48.

Awerbuch, L. 1998. The Status of Desalination Technology, Trends. Second IDA International Desalination Conference in Egypt (Cairo) 7-8 October 1998.

Bleninger, T. 2006. Coupled 3D hydrodynamic models for submarine outfalls: Environmental hydraulic design and control of multiport diffusers, Ph.D. Dissertation, Institute for Hydromechanics, University of Karlsruhe.

Bleninger, T. and G.H. Jirka. 2010. Environmental planning, prediction and management of brine discharges from desalination plants, Middle East Desalination Research Center (MEDRC).

Bleninger, T., A. Niepelt and G.H. Jirka. 2010. Desalination plant discharge calculator, Desalination and Water Treatment, 13, 2010, 156-173.

Boeuf, G. and P. Payan. 2001. How should salinity influence fish growth? Comp. Biochem. Physiol. C $130,411-423$

Bower, A.S., H.D. Hunt and J.F. Price. 2000. Character and dynamics of the Red Sea and Persian Gulf outflows. J.G.R., vol. 105, pp. 6387-6414.

Brown, B.E. 1997. Coral Bleaching: Causes and Consequences. Coral Reefs 16.0, S129-138.

Burchett, M.D., C.J. Clarke, C.D. Field and A. Pulkownik. 1989. Growth and Respiration in Two Mangrove Species at a Range of Salinities. Physiologia Plantarum 75.2: 299-303.

Cooley, H., P.H. Gleick and G. Wolff. 2006. Desalination, with a grain of salt. A California Perspective: Pacific Institute for Studies in Development, Environment and Security: Oakland, California.

Dana, G. and P. Lenz. 1986. Effects of increasing salinity on anArtemia population from Mono Lake, California. Ecology (Berlin) 68(3): 428-436.

Dawoud M.A. and M. Al Mulla. 2012. Environmental impacts of seawater desalination: Arabian Gulf case study. Int J Environ Sustain 2012; 1(3): 22-37.

Deltares. 2011. Deft3D-Flow user manual, Delft, Netherlands.

Dupavillon, J.L. and B.M. Gillanders. 2009. Impacts of Seawater Desalination on the Giant Australian Cuttlefish Sepia Apama in the Upper Spencer Gulf, South Australia. Marine Environmental Research 67.4-5: 207-218.

Egbert G.D. and S.Y. Erofeeva. 2002. Efficient inverse modelling of barotropic ocean tides, J. Atmos. Ocean. Tech., 19.

Einav, R., K. Harussi and D. Perry. 2002. The footprint of the Desalination Processes on the Environment. Desalination 152, 141-154.

Elhakeem A.A. 2014. Hydrodynamic Evaluation Of Climate Change and Coastal Effluents Effects on the Arabian Gulf Long-Term Circulation and its Impacts On Desalination, Ph.D Dissertation, United Arab Emirates University, UAE.

Elhakeem, A., W. Elshorbagy and T. Bleninger. 2015. Long-term hydrodynamic modeling of the Arabian Gulf. Mar. Pollut. Bull. 94, 19-36. http://dx.doi.org/10.1016/j.marpolbul. 2015.03.020. 
Elimelech M. and W.A. Phillip. 2011. The future of seawater de-salination: energy, technology, and the environment. Science, Sci.05 Aug 2011: Vol. 333, Issue 6043, pp. 712-717

ElNesr, M.N., A.A. Alazaba and M.T. Amin. 2011. Modified Hargreaves' Method as an alternative to Penman-monteith method in the Kingdom of Saudi Arabia. Aust. J. Basic Appl. Sci. 5 (6), 10581069.

Emery, K.O. 1956. Sediments and Water of the Persian Gulf, AAPG Bull., 40, pp. 2354-2383.

GEBCO_2014 grid, 2014. GEneral Bathymetric Chart of the Oceans, https://www.bodc.ac.uk/data/ online delivery/gebco/ (accessed May. 2016).

GWI. 2010. GWI Desalination Market Forecast March: DesalForecastMarch2010.xls.

Hastenrath, S. and P.J. Lamb. 1979. Climatic Atlas of the Indian Ocean, Part 2, The Ocean Heat Budget. Univ. of Wisc. Press, Madison, Wisconsin.

Hart B.T., P.S. Lake, J.A. Webb and M.R. Grace. 2003. Ecological risk to aquatic systems from salinity increases. Australian Journal of Botany, 51, 689-702.

Hopner, T. 1999. A procedure for environmental impact assessments (EIA) for seawater desalination plants. Desalination 172: 207-214.

Immerzeel, W., P. Droogers, W. Terink, J. Hoogeveen, P. Hellegers and M. Bierkens. 2011. MiddleEast and Northern Africa Water Outlook, FutureWater Report No. 98, FutureWater, Wageningen, January.

IPCC, Intergovernmental Panel on Climate Change. 2014. Climate Change 2014: Mitigation of Climate Change. Contribution of Working Group III to the Fifth Assessment Report of the Intergovernmental Panel on Climate Change [Edenhofer, O., R. Pichs-Madruga, Y. Sokona, E. Farahani, S. Kadner, K. Seyboth, A. Adler, I. Baum, S. Brunner, P. Eickemeier, B. Kriemann, J. Savolainen, S. Schlömer, C. von Stechow, T. Zwickel and J.C. Minx (eds.)]. Cambridge University Press, Cambridge, United Kingdom and New York, NY, USA.

Kämpf. J. and M. Sadrinasab. 2006. The Circulation of the Persian Gulf: A Numerical Study. Oc. Sci., 2, 27-41.

Kumar S.P. and T.G. Prasad. 1999. Formation and spreading of Arabian Sea High-Salinity Water mass. J Geophys Res 104:1455-1464. doi:10.1029/1998JC900022.

Lattemann, S. and T. Hopner. 2008. Environmental Impact and Impact Assessment of Seawater Desalination. Desalination 220.1-3: 1-15.

Latteman, S., R. Morelissen and J. Gils. 2013. Desalination capacity of the Arabian Gulf modelling. Monitoring and Managing Discharges. International Desalination Association World Congress on Desalination and Water Reuse. Tianjin, China.

Meshal, A.H. and H.M. Hassan. 1986. Evaporation from the coastal water of the central part of the Gulf. Arab Gulf J. Sci. Res. 4: 649-655.

Mickley, M. 1995. Environmental considerations for the disposal of desalination concentrates. Desalination and Water Reuse 54, 56-61.

Morelissen, R., R. de Graaff, P. Visser, T. Minns, T. Pokavanich, et al. 2016. Three-dimensional numerical modelling of the Arabian Gulf Community Model, Arabain Coastal Conference, Presentation.

Mosaddad, S.M. and M. Delphi. 2013. A Numerical Study of Thermocline in the Persian Gulf. MiddleEast Journal of Scientific Research 13.6 : 772-780.

Privett, D.W. 1959. Monthly charts of evaporation from the North Indian Ocean, including the Red Sea and the Persian Gulf. Q.J. Roy. Meteor. Soc. 85, 424-428.

Pous, S., P. Lazure and X. Carton. 2015. A model of the general circulation in the Persian Gulf and in the Strait of Hormuz: Intraseasonal to interannual variability, Cont. Shelf Res., 94, 55-70.

Premchand, K., J.S. Sastry and C.S. Murty. 1986. Water mass structure in the western Indian Ocean, II, The sprcading and transportation of Persian Gulf water, Mausam, 37, 179-186.

Purnama, A., H. Al barwani and R. Smith. 2005. Calculating the Environmental Cost of Seawater Desalination in the Arabian Marginal Seas. Desalination 185.1-3: 79-86.

Reynolds, R.M. 1993. Physical oceanography of the Gulf, Strait of Hormuz, and the Gulf of Oman Results from the Mt Mitchell expedition. Mar. Pollut. Bull. 27: 35-59.

Saha, S., S. Moorthi, H. Pan et al., 2010. NCEP Climate Forecast System Reanalysis (CFSR) Selected Hourly Time-Series Products, January 1979 to December 2010. Research Data Archive at the National Center for Atmospheric Research, Computational and Information Systems Laboratory. http://dx.doi.org/10.5065/D6513W89. Accessed 03 Jul 2016. 
Saha, S., S. Moorthi, X. Wu, et al., 2012. NCEP Climate Forecast System Version 2 (CFSv2) Monthly Products. Research Data Archive at the National Center for Atmospheric Research, Computational and Information Systems Laboratory. http://dx.doi.org/10.5065/D69021ZF. Accessed 03 Jul 2016.

Schiffler, M. 2004. Perspective and challenges for desalination in the 21st century. Desalination 165 : $1-9$.

Sheppard, C., M. Al-Husiani, F. Al-Jamli, F. Al-Yamani, R. Baldwin, et al. 2010. The Gulf: A Young Sea in Decline. Marine Pollution Bulletin 60.1 (2010): 13-38.

Sultan, S.A.R. and N.M. Elghribi. 2002. Heat budget of the southeastern part of the Arabian Gulf. Indian J. Mar. Sci. 31 (1).

Talavera, J. and J. Ruiz. 2001. Identification of the mixing processes in brine discharges carried out in Barranco del Toro Beach, south of Gran Canaria (Canary Islands). Desalination 139, 277-286.

Uddin, S. 2014. Environmental impacts of desalination activities in the Arabian Gulf. Int. J. Environ. Sci. Dev. 5, 114-117.

UN. 2017. United Nations World Population Prospects. The 2017 Revision Population Database https://esa.un.org/unpd/wpp/Graphs/Probabilistic/POP/TOT/ accessed on Aug.2017

Verdier, F., R. Baten, H. Ludwig, F. Trieb, M. Moser, et al. 2011. Water supply model — Desalination using renewable energies, MENA Regional Water Outlook, Phase 1, Final Report, study by Fichtner, FutureWater and DLR, commissioned by World Bank. Available from: www.dlr.de/tt/menawater.

Wangnick, K. 2000. 2000 IDA Worldwide Desalting Plants Inventory Report - no. 16; up to 31 December 1999', Issued May 2000: Wangnick Consulting GMBH; sponsored by IDA May 2000.

Willmott, C. J., S. M. Robeson and K. Matsuura. 2012. A refined index of model performance. Int. J. Climatol., 32: 2088-2094. doi:10.1002/joc.2419.

Xue, P. and E.A.B. Eltahir. 2015. Estimation of the Heat and Water Budgets of the Persian (Arabian) Gulf Using a Regional Climate Model, Journal of Climate 28.13 : 5041-5062. 